\title{
Age at surgery is correlated with pain scores following trochlear osteotomy in lateral patellar instability: a cross-sectional study of 113 cases
}

Jordy D. P. van Sambeeck* (D, Nico Verdonschot, Albert Van Kampen and Sebastiaan A. W. van de Groes

\begin{abstract}
Background: A trochlear osteotomy aims to restore patellar stability in patients with recurrent patellar instability and trochlear dysplasia. The age of patients at time of surgery could be a relevant factor which influences outcome. We hypothesized that lower age at time of surgery is associated with better patient-reported outcomes.

Methods: A retrospective study was conducted on patients with patellar instability and trochlear dysplasia. Patients were contacted by phone for informed consent and were then asked to complete online patient-reported outcome measurements (PROMs). The PROMs consisted of the Kujala Knee Score (KKS) (Kujala et al., Arthroscopy 9(2):159-63, 1993; Kievit et al. Knee Surg Sports Traumatol Arthrosc. 21(11):2647-53, 2013), the Short Form 36-item health survey (SF-36v1) (Ware, Med Care 73-83, 1992; Aaronson et al., J Clin Epidemiol. 51(11):1055-68, 1998), and visual analog scale (VAS) scoring pain, instability, disability, and satisfaction on a 0-100 scale. Multivariable linear regression models were used to study the effect of age on the PROM scores.
\end{abstract}

Results: For this study, 125 surgical procedures in 113 patients were included. Mean VAS pain at rest was 19 and at activity 38; mean Kujala score was 73. Multivariable regression analysis revealed that age at the time of surgery was correlated with VAS pain at rest, with a 0.95 increase of VAS score (scale 0-100) for every year of age. Recurrence of instability was observed in $13(10 \%)$ knees.

Conclusion: In this cross-sectional study, pain scores of 113 patients who have undergone a lateral facet elevating trochlear osteotomy for patellar instability were reported. Age at time of surgery was correlated with an increased pain score at rest with an average of 9.5 points (scale $0-100$ ) for every 10 years of age. Age at time of surgery was not correlated with overall satisfaction.

Keywords: Patella, Patellofemoral joint, Patellar instability, Trochlear dysplasia, Trochlear osteotomy

* Correspondence: jordyvansambeeck@gmail.com

Department of Orthopaedic Surgery, Radboudumc, PO Box 9101, 6500, HB,

Nijmegen, the Netherlands

(c) The Author(s). 2021 Open Access This article is licensed under a Creative Commons Attribution 4.0 International License, which permits use, sharing, adaptation, distribution and reproduction in any medium or format, as long as you give appropriate credit to the original author(s) and the source, provide a link to the Creative Commons licence, and indicate if changes were made. The images or other third party material in this article are included in the article's Creative Commons licence, unless indicated otherwise in a credit line to the material. If material is not included in the article's Creative Commons licence and your intended use is not permitted by statutory regulation or exceeds the permitted use, you will need to obtain permission directly from the copyright holder. To view a copy of this licence, visit http://creativecommons.org/licenses/by/4.0/ The Creative Commons Public Domain Dedication waiver (http://creativecommons.org/publicdomain/zero/1.0/) applies to the data made available in this article, unless otherwise stated in a credit line to the data. 


\section{Background}

Patellar instability is a common problem seen by orthopedic surgeons. The annual incidence of primary patellar dislocation has been estimated at 43 per 100,000 in children under 16 years [1]. Recurrent patellar dislocation occurs in 15 to $45 \%$ of primary dislocation cases [2-7]. Patellofemoral stability is maintained by static stabilization of bony and soft tissue structures on the one hand and by dynamic stabilization through the activation of muscles on the other hand. The lateral displacement is statically restrained by the lateral facet of the trochlea and the medial patellofemoral ligament (MPFL) and mechanical alignment. Dynamic stabilization occurs by the activation and relaxation of coacting muscles and muscle groups that directly or indirectly influence the position of the patella relative to the trochlea. Trochlear dysplasia is a condition in which the development of the trochlea results in an abnormal geometry, with a shallow, flat, or a convex shape of the sulcus. It has been identified as the most consistent anatomic factor present in patients with recurrent patellar dislocations [8]. In patients without pathoanatomical risk factors such as trochlear dysplasia, isolated MPFL reconstruction has a reliable outcome $[9,10]$. A trochlear osteotomy could be added to the procedure for the surgical treatment of patients with recurrent patellar dislocations and trochlear dysplasia. Various surgical procedures have been described to reshape the abnormal trochlea $[11,12]$. Trochlear osteotomies directly modify the patellofemoral joint with the risk of causing cartilage damage and alteration of joint kinematics and contact pressures [12]. Normal joint kinematics and contact pressures are fundamental for the long-term joint preservation, and abnormalities in these factors could potentially lead to development of early patellofemoral osteoarthritis [11-14]. Due to the presumed susceptibility of complications of a trochlear osteotomy, these procedures are not performed often. However, a systematic review of literature demonstrated that the rate of major complications is comparable to those of other patellar stabilizing procedures [15].

The indication for trochlear osteotomies is still a matter of debate. Combination of the procedure with another bony or soft tissue procedure is often necessary to achieve patellar stability throughout the full range of knee motion. Patellar stability is reported to be restored in a large majority of patients who had a trochlear osteotomy $[11,16,17]$.

Next to the anatomical abnormalities such as trochlear dysplasia, patella alta, and insufficiency of the MPFL and MPTL [18], other patient factors such as their age could be of influence on the results of surgery for patellar instability. Multiple studies have shown that a correlation exists between the age of patients and the risk on recurrent dislocation and the outcomes of surgery. A study of Fithian et al. indicated that patients with initial injury at a younger age had a higher risk of subsequent patellar subluxation or dislocation [7]. Hiemstra et al. found a correlation between age at time of surgery (MPFL reconstruction) and outcome [19]. Palmu et al. [20] reported a redislocation rate of $67 \%$ following operative treatment for acute patellar dislocation in children younger than 16 years of age, which is much higher than the pooled risk of redislocation of $12 \%$ presented by Smith et al. [21] in their systematic review. Age at time of surgery might therefore be a factor for the risk of redislocation and patient-reported outcome of surgery. In addition to these correlations, adolescent patients are expected to have more pliable osseocartilaginous structures than the older patients [22]; this might lead to less cartilage damage by focal aseptic necrosis, better malleability, and therefore better clinical results in patients of a younger age.

The main goal of this study was to evaluate the effect of age on patient-reported outcome after a lateral facet elevating trochlear osteotomy in a large cohort.

We hypothesized that lower age at time of surgery is associated with better patient-reported outcomes.

\section{Methods \\ Patients}

Data for this study was collected retrospectively. Patients who have undergone a lateral facet elevating trochlear osteotomy to restore patellar stability in Radboudumc, Nijmegen, between 2005 and 2015 were included in this study. All operations were carried out by one senior orthopedic surgeon (AK) using the same surgical technique over time (described below). Indications for trochlear osteotomy were recurrent patellar dislocation or subluxation in the presence of a positive J-sign and radiographically confirmed trochlear dysplasia on a true lateral X-ray according to the criteria of Dejour and Saggin [23]. Radiologically closed epiphyses stage 3 or 4 (scale range 0-4) was confirmed in all patients; this was scaled according to the method described by O'Connor et al. [24]. Stage 3 indicates recent union, and stage 4 indicates complete union when remodeling has taken place and there is continuity of trabeculae form shaft to former epiphysis.

This study was approved by the Medical Ethical Review Board of the Radboudumc, Nijmegen, The Netherlands (CMO 2015-1943).

\section{Methods of assessment}

The research team contacted each participant by phone to explain the study and have the participants complete patient-reported outcome measurements (PROMs). A secured website was used to complete reports. The PROMs included the Kujala Knee Score (KKS) [25, 26], the Short Form 36-item health survey (SF-36v1) [27, 28], and visual analog scale (VAS) scoring pain, instability, disability, and satisfaction. At time of surgery, no preoperative or postoperative PROMs were collected. Due to the retrospective nature of this study, those data are lacking and are not included in the analysis. 


\section{Statistical analysis}

Descriptive statistics was used to summarize the data. Multivariable linear regression models were used to evaluate the association between age (independent variable) and VAS and KKS scores (dependent variables). Based on clinical experience and published literature, we selected gender, history of surgery, presence of low or high grade trochlear dysplasia (low vs. high grade: A or C vs. B or D), postoperative patellar height, $\mathrm{BMI}$, and whether or not additional procedures were performed as independent variables that could influence patient-reported outcome of surgery [29-31]. The multivariable regression analysis adjusts for these factors. Due to a lack of data, BMI as independent variable was not taken into account for analysis. A P-value of $<0.05$ was considered statistically significant. All statistical analyses were performed using SPSS (v20, IBM SPSS Statistics, Armonk, NY, USA).

\section{Surgical technique}

A surgical technique was used as previously described by Koëter et al. [32] and slightly differs from the lateral facet elevating trochlear osteotomy as described by Albee and Weiker [33, 34]. In brief, the patient was placed supine on the table. Antibiotics were admitted preoperatively. No tourniquet was used. A lateral parapatellar incision was made and extended distally along the lateral femoral condyle. The retinaculum was opened in the direction of the femur. To visualize the osteotomy, two Kirschner wires were placed in the direction of the osteotomy till they were visible through the cartilage (halfway between the medial and lateral femoral facet). With the use of a small osteotome, an incomplete lateral trochlear osteotomy was carried out (Fig. 1). The curved osteotomy extended from the beginning of the trochlea proximally to the sulcus terminalis distally. Subsequently, the lateral articular surface of the trochlea was levered. In most cases, it was possible to raise the lateral articular surface by $4-6 \mathrm{~mm}$. A wedge-shaped autograft was created with a part of the ipsilateral iliac crest

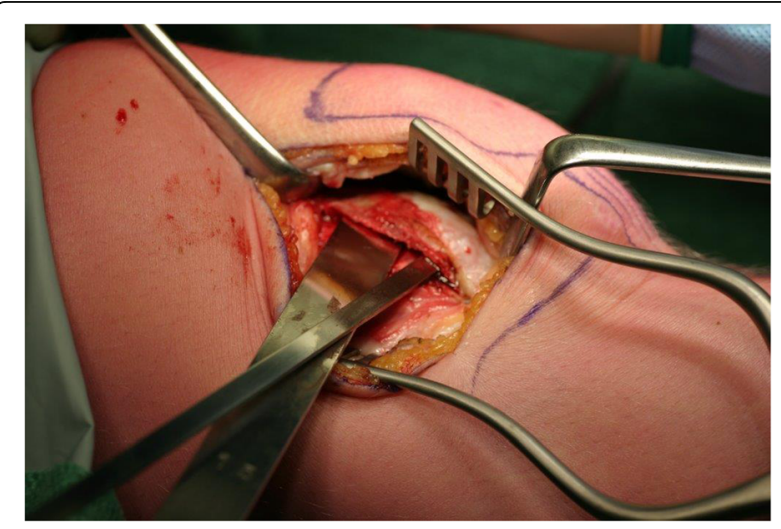

Fig. 1 The osteotomy is performed with osteotomes; the proximal is further advanced medially than the distal osteotome to secure the elevation of the osteotomy; this graft was changed to a tricalcium phosphate (TCP) wedge during the study period (Fig. 2). Fixation of the osteotomy with osteosynthesis material was not needed. After performance of the osteotomy, the synovium was closed over while the lateral retinaculum was left open. Postoperatively, patients were placed on a continuous passive motion device (CPM) to stimulate a full passive range of motion until knee flexion was at least $60^{\circ}$. Patients were recommended the following training schedule: partial weight bearing for the first 6 weeks, without flexion limitation. After 6 weeks, full weight bearing was allowed. Patients were only referred to a physical therapist if restoration of normal gait was needed.

\section{Results}

The patient database of our hospital identified 180 trochlear osteotomies in 150 unique patients, of whom $37 \mathrm{pa}-$ tients (55 procedures) could not be contacted or refused to participate. This led to the inclusion of 113 patients with 125 surgical procedures. Twelve patients had undergone bilateral trochlear osteotomy. Demographics and mean outcome scores are displayed in Table 1. Nine patients had no true lateral X-ray available in the database and were therefore not retrospectively classified into one of the four types of trochlear dysplasia.

The mean VAS for pain at rest was 19 while this was 38 during activity. The mean VAS for overall satisfaction was 66 . The mean KKS was 73, and the mean SF-36 general health perception was 72 (Table 1). In our cohort of patients with a mean age of 19.8 years (range 12.5-46.3) at surgery, multivariable regression analysis (Tables 2 and 3 and Tables 4, 5, 6 and 7 in the Appendix) revealed a correlation between age at time of surgery and VAS pain at rest. The VAS pain score at rest increased with $0.95(0-100$ scale) with every year of age at time of surgery (P 0.025). Recurrence of instability was seen in $13(10 \%)$ knees.

Complications included a postoperative flexion deficit in four knees. In one knee of a female patient at the age

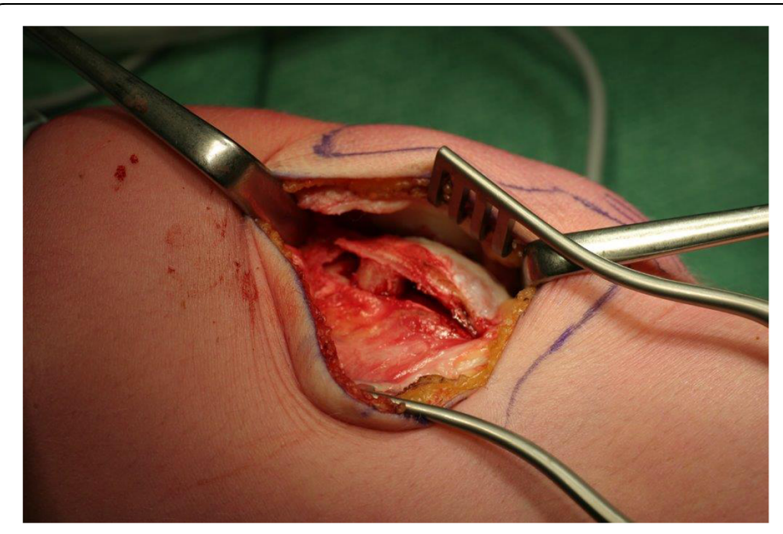

Fig. 2 A triangular bone graft or tricalcium phosphate wedge is used to hold the achieved correction 
Table 1 Demographic characteristics and outcome scores

\begin{tabular}{|c|c|}
\hline Age at surgery in years (range) & $19.8(12.5-46.3)$ \\
\hline Follow-up time (months) & $71(12-125)$ \\
\hline \multicolumn{2}{|l|}{ Gender } \\
\hline Female (\%) & $102(82)$ \\
\hline \multicolumn{2}{|l|}{ Type of trochlear dysplasia (\%) } \\
\hline Type A & $14(12)$ \\
\hline Type B & $55(49)$ \\
\hline Type C & $9(8)$ \\
\hline Type D & $33(29)$ \\
\hline Previous procedures (\%) & $16(13)$ \\
\hline Additional procedures (\%) & $69(55)$ \\
\hline MPFL reconstruction & $7(5.6)$ \\
\hline Tibial tuberosity transfer & $63(50)$ \\
\hline Complications during follow-up (\%) & $9(7)$ \\
\hline Flexion deficit & $4(3)$ \\
\hline Persisting instability & $1(1)$ \\
\hline Removal TCP wedge & $2(2)$ \\
\hline Break-out of osteotomy & $1(1)$ \\
\hline Venous thromboembolic event & $1(1)$ \\
\hline \multicolumn{2}{|l|}{ Outcome score } \\
\hline VAS pain at rest & $19(0-80)$ \\
\hline VAS pain at activity & $38(0-90)$ \\
\hline VAS instability & $40(0-100)$ \\
\hline VAS disability & $34(0-100)$ \\
\hline VAS satisfaction & $66(1-100)$ \\
\hline Kujala Knee Score & $73(17-100)$ \\
\hline SF-36 General health & $72(10-100)$ \\
\hline
\end{tabular}

Values represent mean with range, unless otherwise indicated. $\mathrm{N}$ is number of knees unless otherwise indicated

Table 2 Results of multivariable regression analysis for VAS pain rest as dependent variable

\begin{tabular}{lll}
\hline $\begin{array}{l}\text { Risk factor (independent } \\
\text { variable) }\end{array}$ & $\begin{array}{l}\text { Multivariable regression } \\
\text { coefficient }(\mathbf{9 5 \%} \mathbf{C l})\end{array}$ & $\boldsymbol{P}$-value \\
\hline Age at time of surgery & $\mathbf{0 . 9 5}(\mathbf{0 . 1 2} \mathbf{1 . 8})$ & $\mathbf{0 . 0 2 5}$ \\
Female & $\mathbf{1 2 . 7}(\mathbf{1 . 1}, \mathbf{2 4 . 3 )}$ & $\mathbf{0 . 0 3 2}$ \\
Previous procedures performed & $10.3(-3.9,24.5)$ & 0.15 \\
Patellar height & $0.12(-23.0,23.2)$ & 0.99 \\
$\begin{array}{l}\text { Trochlear dysplasia A or C vs. B } \\
\text { or D }\end{array}$ & $-2.5(-13.8,8.8)$ & 0.66 \\
Additional MPFL reconstruction & $-2.8(-24.7,19.1)$ & 0.80 \\
Additional tibial tubercle transfer & $-0.52(-10.0,9.0)$ & 0.91 \\
\hline
\end{tabular}

Cl confidence interval

Bold risk factor: statistically significant
Table 3 Results of multivariable regression analysis for Kujala Knee Score as dependent variable

\begin{tabular}{|c|c|c|}
\hline $\begin{array}{l}\text { Risk factor (independent } \\
\text { variable) }\end{array}$ & $\begin{array}{l}\text { Multivariable regression } \\
\text { coefficient }(95 \% \mathrm{Cl})\end{array}$ & $P$-value \\
\hline Age at time of surgery & $-0.47(-1.0,0.17)$ & 0.15 \\
\hline Female & $-11.6(-20.4,-2.7)$ & 0.011 \\
\hline Previous procedures performed & $-16.2(-27.1,-5.3)$ & 0.004 \\
\hline Patellar height & $-11.6(-29.2,6.1)$ & 0.20 \\
\hline $\begin{array}{l}\text { Trochlear dysplasia A or C vs. B } \\
\text { or D }\end{array}$ & $2.6(-6.1,11.3)$ & 0.55 \\
\hline Additional MPFL reconstruction & $5.8(-11.0,22.6)$ & 0.49 \\
\hline Additional tibial tubercle transfer & $0.94(-6.3,8.2)$ & 0.80 \\
\hline
\end{tabular}

Bold risk factor: statistically significant

of 47 years at time of surgery, postoperatively, the trochlear osteotomy broke out to the distal femoral condyle; open reduction and refixation with two screws was performed; however, it resulted in arthrofibrosis and patellofemoral osteoarthritis (PF OA). One patient had persisting instability together with $\mathrm{PF} \mathrm{OA}$ in the knee and underwent a patellofemoral arthroplasty 1 year postoperatively; in two patients, the tricalcium phosphate (TCP) wedge was removed because of dislocation, in one patient it dislocated, and in one patient this wedge broke, and one patient had deep venous thrombosis.

\section{Discussion}

In this study, we showed that a VAS pain score increased with higher age after a lateral facet elevating trochlear osteotomy. Although the increase is relatively small for every year of age (0.95), it is a clinically relevant increase for every 10 years of age (9.5).

This study was not designed to investigate the underlying cause of increased pain; however, the following hypothesis could well be true. Older patients have a longer history of patellofemoral instability (peak incidence of first dislocation is in adolescence [7]). They might have a history of patellar dislocations with a longer period of maltracking of the patella. As a consequence, increased cartilage damage and degenerative changes of the patellofemoral joint would be present at time of surgery. This might have an influence on the level of correction that is possible, the congruency of the new trochlea, the presence of microtears during surgery, and the load-bearing capacity of the cartilage. These factors could also be influenced by the pliability of the articular cartilage, which decreases with increasing age due to molecular changes. Despite the fact that increasing age is correlated with a higher VAS pain score at rest in our study, we do not assume that this is caused by early PF OA. Although the present study did not evaluate the radiological presence of PF OA, a study by Tigchelaar et al. [35] showed no clear correlation between VAS pain and the grade of PF OA after trochlear osteotomy. They analyzed data from patients with 
12 years of follow-up. Radiological PF OA after surgery was generally limited to lower grades on the Iwano scale [35]. In our study, two older patients (age at surgery 27 and 46 years) had radiologically confirmed PF OA during followup; this was radiologically examined because of the presence of persisting pain. Both patients scored high on VAS pain at rest and therefore contributed to an overall increased average in our study. Early symptomatic PF AO is not expected to be the main reason for an increase in mean VAS score at higher age. We hypothesize that decreased adaptation of the cartilage to the new situation results in increased subchondral pressure and higher pain scores at rest.

Age at time of surgery did not have a significant effect on other outcome measurements. However, it should be noticed that a relatively high rate of redislocation after trochlear osteotomy (10\%) was found. Age of these patients ranged between 12 and 22 years with an average of 16 years and is lower than the average age of patients in our cohort (19.8 years). Furthermore, results of the multivariate linear regression analysis revealed significantly higher VAS instability score in females vs. males. With the exception of gender, no other risk factors were significantly correlated with VAS instability. In our cohort, an additional MPFL reconstruction was only performed in $5.6 \%$ of patients. Recently published literature and new surgical techniques for MPFL reconstruction have narrowed the indication for an isolated trochlear osteotomy without MPFL reconstruction. An additional MPFL reconstruction probably decreases the rate of redislocation. With this in mind, a redislocation rate of $10 \%$ can be seen as proof of the effectiveness of a trochlear osteotomy in terms of stability.

The mean KKS in our study was 73; this is an acceptable score in our opinion. The systematic review of Balcarek et al. demonstrates higher KKS scores after trochleoplasty procedures (range 81-92) [36]. However, due to the inclusion and exclusion criteria (for example the exclusion of studies in which treatment included additional procedures) of their review, it is difficult to compare our cohort with the studies they have included.

Loss in range of motion occurred in four patients (2\%), which was lower in our study than in previously published reports [15]. The standard use of a CPM might have contributed to this. Four patients had a complication related to the TCP wedge.

The results of our study, including a relatively high rate of patellar redislocation and KKS of 73, emphasize that patient selection and strict indication for this type of trochleoplasty is highly important for a better outcome. A recent consensus statement from the AOSSM/ PFF Patellofemoral Instability Workshop as well as recent guidelines stated that trochleoplasty is rarely indicated in patients with patellar instability [37, 38]. In determining whether surgery for recurrent patellar instability is warranted, trochlear morphology, patellar height, lateralization of the tibial tubercle, sufficiency of the MPFL, age, and gender should be considered. None of the different types of dysplasia according to Dejour and Saggin was correlated with outcome measurements of this study. The indications for a lateral facet elevating trochlear osteotomy have decreased in recent years. However, we think that there is still a place for this type of trochlear osteotomy in patients with recurrent patellar dislocation with a J-sign at physical exam, underlying trochlear dysplasia without a trochlear bump but with a convex proximal trochlea. In these cases, outcomes are most predictable, and the risk of serious complications is low.

This is the first study to investigate the effect of age on the postoperative outcomes of a lateral facet elevating trochlear osteotomy. The strength of this study is the large patient cohort and the use of PROMs which reflect the outcome as experienced by patients and not based on radiographs assessed by clinicians. Despite the minimal number of indications, we are convinced that it is important to present the outcomes of this type of trochlear osteotomy, studied in a large cohort, in the perspective of personalized treatment for the individual patient.

Our study also has some potential limitations. First, our study population was heterogenic (e.g., different types of dysplasia, multiple additional procedures). Although intrinsic heterogeneity in patient characteristics and treatment strategy exists in this study, we think that this population reflects the patients seen during daily practice. Second, patients were not physically examined by a clinician. Our study demonstrates that patient-reported outcomes, in conjunction with surgical complications, are most relevant to determine post-surgical outcome. This warrants the use of PROMs in this patient category. Third, a difference in the level of preoperative chondropathy between younger and older patients could influence postoperative outcome, but a quantifiable report on the preoperative chondral status is lacking in our study. A lot of patients with patellar luxation or subluxation have some amount of patellofemoral chondropathy; this is inherent to the underlying pathology. It has not been demonstrated that preoperative chondral status is associated with postoperative outcome. However, a surgeon should be aware of the possible interaction of chondral status and outcome of surgery.

\section{Conclusion}

In this cross-sectional study, pain scores of 113 patients who have undergone a lateral facet elevating trochlear osteotomy for patellar instability were reported. Age at time of surgery was correlated with an increased pain score at rest with an average of 9.5 points (scale $0-100$ ) for every 10 years of age. Age at time of surgery was not correlated with overall satisfaction. 


\section{Appendix}

Table 4 Results of multivariable regression analysis for VAS pain activity as dependent variable

\begin{tabular}{lll}
\hline $\begin{array}{l}\text { Risk factor (independent } \\
\text { variable) }\end{array}$ & $\begin{array}{l}\text { Multivariable regression } \\
\text { coefficient }(\mathbf{9 5 \%} \mathbf{C l})\end{array}$ & $\boldsymbol{P}$-value \\
\hline Age at time of surgery & $0.79(-0.23,1.8)$ & 0.13 \\
Female & $\mathbf{2 1 . 0}(\mathbf{6 . 8}, \mathbf{2 3 . 3 )}$ & $\mathbf{0 . 0 0 4}$ \\
Previous procedures performed & $14.8(-2.7,32.2)$ & 0.096 \\
Patellar height & $9.9(-18.5,38.3)$ & 0.49 \\
$\begin{array}{l}\text { Trochlear dysplasia A or C vs. B } \\
\text { or D }\end{array}$ & $-8.0(-21.9,6.0)$ & 0.26 \\
Additional MPFL reconstruction & $1.8(-25.1,28.8)$ & 0.89 \\
Additional tibial tubercle transfer & $-4.4(-16.0,7.4)$ & 0.46 \\
\hline
\end{tabular}

$\mathrm{Cl}$ confidence interval

Bold risk factor: statistically significant

Table 5 Results of multivariable regression analysis for VAS instability as dependent variable

\begin{tabular}{lll}
\hline $\begin{array}{l}\text { Risk factor (independent } \\
\text { variable) }\end{array}$ & $\begin{array}{l}\text { Multivariable regression } \\
\text { coefficient }(\mathbf{9 5 \%} \mathbf{C l})\end{array}$ & $\boldsymbol{P}$-value \\
\hline Age at time of surgery & $-0.22(-1.4,0.96)$ & 0.71 \\
Female & $\mathbf{1 7 . 2}(\mathbf{0 . 5 8 , 3 3 . 8 )}$ & $\mathbf{0 . 0 4 3}$ \\
Previous procedures performed & $7.6(-12.7,27.8)$ & 0.46 \\
Patellar height & $19.4(-13.6,52.4)$ & 0.25 \\
Trochlear dysplasia A or & $4.9(-11.3,21.2)$ & 0.55 \\
C vs. B or D & & \\
Additional MPFL reconstruction & $-1.5(-32.9,29.8)$ & 0.92 \\
Additional tibial tubercle transfer & $1.4(-12.2,15.0)$ & 0.84 \\
\hline
\end{tabular}

$\mathrm{Cl}$ confidence interval

Bold risk factor: statistically significant

Table 6 Results of multivariable regression analysis for VAS disability as dependent variable

\begin{tabular}{lll}
\hline $\begin{array}{l}\text { Risk factor (independent } \\
\text { variable) }\end{array}$ & $\begin{array}{l}\text { Multivariable regression } \\
\text { coefficient }(\mathbf{9 5 \%} \mathbf{C l})\end{array}$ & $\boldsymbol{P}$-value \\
\hline Age at time of surgery & $0.13(-1.0,1.3)$ & 0.82 \\
Female & $8.6(-7.4,24.6)$ & 0.29 \\
Previous procedures performed & $17.1(-2.5,36.7)$ & 0.086 \\
$\begin{array}{l}\text { Patellar height } \\
\text { Trochlear dysplasia A or C vs. B }\end{array}$ & $10.6(-21.2,42.4)$ & 0.51 \\
$\begin{array}{l}\text { or D } \\
\text { Additional MPFL reconstruction }\end{array}$ & $-12.7(-42.2,26.1)$ & 0.19 \\
Additional tibial tubercle transfer & $2.1(-11.1,15.2)$ & 0.41 \\
\hline
\end{tabular}

Cl confidence interval

Bold risk factor: statistically significant
Table 7 Results of multivariable regression analysis for VAS satisfaction as dependent variable

\begin{tabular}{lll}
\hline $\begin{array}{l}\text { Risk factor (independent } \\
\text { variable) }\end{array}$ & $\begin{array}{l}\text { Multivariable regression } \\
\text { coefficient }(\mathbf{9 5} \% \mathbf{C I})\end{array}$ & P-value \\
\hline Age at time of surgery & $-0.25(-1.5,1.0)$ & 0.70 \\
Female & $\mathbf{- 2 2 . 6 ( - 4 0 . 2 , - 4 . 9 )}$ & $\mathbf{0 . 0 1 3}$ \\
Previous procedures performed & $-11.6(-33.2,10.0)$ & 0.29 \\
Patellar height & $-7.5(-42.7,27.6)$ & 0.67 \\
Trochlear dysplasia A or C & $2.8(-14.5,20.1)$ & 0.75 \\
vs. B or D & & \\
Additional MPFL reconstruction & $5.3(-28.0,38.7)$ & 0.75 \\
Additional tibial tubercle transfer & $-2.2(-16.7,12.3)$ & 0.76 \\
\hline
\end{tabular}

$\mathrm{Cl}$ confidence interval

Bold risk factor: statistically significant

\section{Abbreviations}

$\mathrm{Cl}$ : Confidence interval; CPM: Continuous passive motion; IRB: Institutional Review Board; KKS: Kujala Knee Score; MPFL: Medial patellofemoral ligament; NRS: Numeric rating scale; PF: Patellofemoral; PF OA: Patellofemoral osteoarthritis; PROMs: Patient-reported outcome measurements; SF-36: Short form 36-item Health Survey; TCP: Tricalcium phosphate; VAS: Visual analog scale

\section{Acknowledgements}

We thank Radboudumc for their educational support to JS during the initiation phase of this study. We thank Thomas Hoogeboom for his help with statistical analysis.

\section{Authors' contributions}

JS initiated the study by defining the research question and purpose of the study with the help of SG. JS performed the data collection and analysis and drafted the manuscript. SG was the first author to review drafts of the manuscript and gave final approval of the version to be submitted. NV, AK, and $\mathrm{GH}$ were second reviewers of drafts of the article and added important feedback for interpretation of the results and for discussion section. GH performed the statistical analyses. The authors read and approved the final manuscript.

Funding

We have received no funding for this study.

Availability of data and materials

The datasets used and/or analyzed during the current study are available from the corresponding author on reasonable request.

\section{Declarations}

Ethics approval and consent to participate

Institutional review board approval was obtained (CMO 2015-1943). All patients received an information letter and were contacted by telephone for explanation of the study and to obtain verbal informed consent.

Consent for publication

Not applicable

\section{Competing interests}

The authors declare that they have no competing interests.

Received: 23 February 2021 Accepted: 13 May 2021

Published online: 25 May 2021

\section{References}

1. Nietosvaara YAK, Kallio PE. Acute patellar dislocation in children: incidence and associated osteochondral fractures. J Pediatr Orthop. 1994;14(4):513-5. https://doi.org/10.1097/01241398-199407000-00018. 
2. Hawkins RJBR, Garth A. Acute patellar dislocations. The natural history. Am J Sports Med. 1986;14(2):117-20. https://doi.org/10.1177/036354658601400204.

3. Arnbjörnsson A EN, Rydling O, Stockerup R, Ryd L. Natural history of recurrent dislocation of the patella. Long-term results of conservative and operative treatment. J Bone Joint Surg [Br\}. 1992;74-B:140-2.

4. Cash JHJ. Treatment of acute patellar dislocation. Am J Sports Med. 1988; 16(3):244-9. https://doi.org/10.1177/036354658801600308.

5. Lewallen LW, McIntosh AL, Dahm DL. Predictors of recurrent instability after acute patellofemoral dislocation in pediatric and adolescent patients. Am J Sports Med. 2013;41(3):575-81. https://doi.org/10.1177/0363546512472873.

6. Jaquith BPPS. Predictors of recurrent patellar instability in children and adolescents after first-time dislocation. J Pediatr Orthop. 2015;37(7):484-90.

7. Fithian DC, Paxton EW, Stone ML, Silva P, Davis DK, Elias DA, et al. Epidemiology and natural history of acute patellar dislocation. Am J Sports Med. 2004;32(5):1114-21. https://doi.org/10.1177/0363546503260788.

8. Dejour HWG, Nove-Josserand L, Guier C. Factors of patellar instability an anatomic radiographic study. Knee Surg Sports Traumatol Arthrosc. 1994; 2(1):19-26. https://doi.org/10.1007/BF01552649.

9. Migliorini F, Oliva F, Maffulli GD, Eschweiler J, Knobe M, Tingart M, et al. Isolated medial patellofemoral ligament reconstruction for recurrent patellofemoral instability: analysis of outcomes and risk factors. J Orthop Surg Res. 2021;16(1):239. https://doi.org/10.1186/s13018-021-02383-9.

10. Aicale R, Maffulli N. Combined medial patellofemoral and medial patellotibial reconstruction for patellar instability: a PRISMA systematic review. J Orthop Surg Res. 2020;15(1):529. https://doi.org/10.1186/s13018-02 0-02072-z.

11. Ntagiopoulos PG, Byn P, Dejour D. Midterm results of comprehensive surgical reconstruction including sulcus-deepening trochleoplasty in recurrent patellar dislocations with high-grade trochlear dysplasia. Am J Sports Med. 2013;41(5): 998-1004. https://doi.org/10.1177/0363546513482302.

12. Ntagiopoulos PG, Dejour D. Current concepts on trochleoplasty procedures for the surgical treatment of trochlear dysplasia. Knee Surg Sports Traumatol Arthrosc. 2014;22(10):2531-9. https://doi.org/10.1007/s00167-014-3013-6.

13. Mulford JSWC, Eldridge JDJ. Assessment and management of chronic patellofemoral instability. J Bone Joint Surg Br. 2007;89-B:709-16.

14. Mäenpää HLM. Patellofemoral osteoarthritis after patellar dislocation. Clin Orthop Relat Res. 1997;339:156-62.

15. van Sambeeck JDP, van de Groes SAW, Verdonschot N, Hannink G. Trochleoplasty procedures show complication rates similar to other patellarstabilizing procedures. Knee Surg Sports Traumatol Arthrosc. 2018;26(9): 2841-57. https://doi.org/10.1007/s00167-017-4766-5.

16. Beaufils P, Thaunat M, Pujol N, Scheffler S, Rossi R, Carmont M. Trochleoplasty in major trochlear dysplasia: current concepts. Sports Med Arthrosc Rehabil Ther Technol. 2012;4(1):7. https://doi.org/10.1186/1758-2 555-4-7.

17. Pesenti S, Blondel B, Armaganian G, Parratte S, Bollini G, Launay F, et al. The lateral wedge augmentation trochleoplasty in a pediatric population: a 5year follow-up study. J Pediatr Orthop B. 2017;26(5):458-64. https://doi.org/1 0.1097/BPB.0000000000000395.

18. Felli L, Alessio-Mazzola M, Lovisolo S, Capello AG, Formica M, Maffulli N. Anatomy and biomechanics of the medial patellotibial ligament: a systematic review. The Surgeon. 2020. https://doi.org/10.1016/.jsurge.2020.09.005.

19. Hiemstra LA, Kerslake $\mathrm{S}$. Age at time of surgery but not sex is related to outcomes after medial patellofemoral ligament reconstruction. Am J Sports Med. 2019:47(7):1638-44. https://doi.org/10.1177/0363546519841371.

20. Palmu S, Kallio PE, Donell ST, Helenius I, Nietosvaara Y. Acute patellar dislocation in children and adolescents: a randomized clinical trial. J Bone Joint Surg Am. 2008;90(3):463-70. https://doi.org/10.2106/JBJS.G.00072.

21. Smith TO DS, Song F, Hing CB. Surgical versus non-surgical interventions for treating patellar dislocation. Cochrane Database Syst Reviews. 2015;2.

22. Kempson. Relationship between the tensile properties of articular cartilage from the human knee and age. Ann Rheum Dis. 1982;41:508-11.

23. Dejour D, Saggin P. The sulcus deepening trochleoplasty-the Lyon's procedure. Int Orthop. 2010;34(2):311-6. https://doi.org/10.1007/s00264-0090933-8.

24. O'Connor JE, Bogue C, Spence LD, Last J. A method to establish the relationship between chronological age and stage of union from radiographic assessment of epiphyseal fusion at the knee: an Irish population study. J Anat. 2008;212(2):198-209. https://doi.org/10.1111/j.14 69-7580.2007.00847.x.
25. Kujala UMJL, Koskinen SK, Taimela S, Hurne M, Nelimarkka O. Scoring of patellofemoral disorders. Arthroscopy. 1993;9(2):159-63. https://doi.org/10.1 016/50749-8063(05)80366-4.

26. Kievit AJ, Breugem SJ, Sierevelt IN, Heesterbeek PJ, van de Groes SA, Kremers KC, et al. Dutch translation of the Kujala Anterior Knee Pain Scale and validation in patients after knee arthroplasty. Knee Surg Sports Traumatol Arthrosc. 2013;21(11):2647-53. https://doi.org/10.1007/s00167013-2635-4.

27. Ware JE Jr. SC. The MOS 36-Item Short-Form Health Survey (SF-36). Med Care. 1992;30(6):473-83. https://doi.org/10.1097/00005650-199206000-00002.

28. Aaaronson NKMM, Cohen PDA, Essink-Bot ML, Fekkes M, Sanderman R, Sprangers MAG, et al. Translation, validation and norming of the Dutch language version of the SF-36 Health Survey in community and chronic disease populations. J Clin Epidemiol. 1998;51(11):1055-68. https://doi.org/1 0.1016/S0895-4356(98)00097-3.

29. Enderlein D, Nielsen T, Christiansen SE, Fauno P, Lind M. Clinical outcome after reconstruction of the medial patellofemoral ligament in patients with recurrent patella instability. Knee Surg Sports Traumatol Arthrosc. 2014; 22(10):2458-64. https://doi.org/10.1007/s00167-014-3164-5.

30. Kita K, Tanaka Y, Toritsuka Y, Amano H, Uchida R, Takao R, et al. Factors affecting the outcomes of double-bundle medial patellofemoral ligament reconstruction for recurrent patellar dislocations evaluated by multivariate analysis. Am J Sports Med. 2015;43(12):2988-96. https://doi.org/10.1177/03 63546515606102.

31. Fucentese SF, Zingg PO, Schmitt J, Pfirrmann CW, Meyer DC, Koch PP. Classification of trochlear dysplasia as predictor of clinical outcome after trochleoplasty. Knee Surg Sports Traumatol Arthrosc. 2011;19(10):1655-61. https://doi.org/10.1007/s00167-011-1410-7.

32. Koeter S, Pakvis D, van Loon CJ, van Kampen A. Trochlear osteotomy for patellar instability: satisfactory minimum 2-year results in patients with dysplasia of the trochlea. Knee Surg Sports Traumatol Arthrosc. 2007;15(3): 228-32. https://doi.org/10.1007/s00167-006-0174-y.

33. Albee. The bone graft wedge in the treatment of habitual dislocation of the patella. Med Rec. 1915;88(7):257-9.

34. Weiker GTBK. The anterior femoral osteotomy for patellofemoral instability. Am J Knee Surg. 1997;10(4):221-7.

35. Tigchelaar S, van Sambeeck J, Koeter S, van Kampen A. A stand-alone lateral condyle-elevating trochlear osteotomy leads to high residual instability but no excessive increase in patellofemoral osteoarthritis at 12-year follow-up. Knee Surg Sports Traumatol Arthrosc. 2018;26(4):1216-22.

36. Balcarek P, Rehn S, Howells NR, Eldridge JD, Kita K, Dejour D, et al. Results of medial patellofemoral ligament reconstruction compared with trochleoplasty plus individual extensor apparatus balancing in patellar instability caused by severe trochlear dysplasia: a systematic review and meta-analysis. Knee Surg Sports Traumatol Arthrosc. 2017;25(12):3869-77. https://doi.org/10.1007/s00167-016-4365-x.

37. Post WR, Fithian DC. Patellofemoral instability: a consensus statement from the AOSSM/PFF patellofemoral instability workshop. Orthop J Sports Med. 2018;6(1):2325967117750352. https://doi.org/10.1177/2325967117750352.

38. Vetrano M, Oliva F, Bisicchia S, Bossa M, De Carli A, Di Lorenzo L, et al. L.T. first time patellar dislocation guidelines. Muscles Ligaments Tendons J. 2017;7(1):1-10.

\section{Publisher's Note}

Springer Nature remains neutral with regard to jurisdictional claims in published maps and institutional affiliations.

Ready to submit your research? Choose BMC and benefit from:

- fast, convenient online submission

- thorough peer review by experienced researchers in your field

- rapid publication on acceptance

- support for research data, including large and complex data types

- gold Open Access which fosters wider collaboration and increased citations

- maximum visibility for your research: over $100 \mathrm{M}$ website views per year

At BMC, research is always in progress.

Learn more biomedcentral.com/submission 